\title{
Design of a New Silver Jewelry Alloy White 925 Sample for Production Chains
}

\author{
Igor V. Uskova, \\ Vladimir V. Moskvichev ${ }^{\mathrm{b}}$, Danil I. Uskov ${ }^{\mathrm{a}}$, \\ Sergey V. Belyaeva, Valentina I. Anikina ${ }^{a}$, \\ Alexey I. Anikin ${ }^{\mathrm{a}}$ and Alexander V. Stolyarov ${ }^{\mathrm{a}}$ \\ ${ }^{a}$ Siberian Federal University \\ 79 Svobodny, Krasnoyarsk, 660041, Russia \\ ${ }^{b}$ Special Design and Technological Bureau «Nauka» \\ Krasnoyarsk Scientific Centre of SB RAS \\ 53 Mira, Krasnoyarsk, 660049, Russia
}

Based on the analysis of scientific literature and theoretical studies by constructing polythermal incisions of multicomponent systems, offered two of ligatures for the smelting of new alloys based on silver. The article presents the results of pilot studies on acquisition and processing of new alloys. The evaluation of the properties and structure of the obtained cast semi-finished products of the new silver jewelry alloys 925 .

Keywords: jewelry alloy, microstructure, polythermal incisions.

DOI: 10.17516/1999-494X-2015-8-5-621-625.

\section{Разработка нового серебряного ювелирного сплава белого цвета 925-й пробы для изготовления цепей}

\author{
И.В. Усков ${ }^{a}$, В.В. Москвичев ${ }^{\sigma}$, Д.И. Усков \\ С.В. Беляев ${ }^{\text {a, В.И. Аникина }}$, А.И. Аникин ${ }^{\text {a }, ~ А . В . ~ С т о л я р о в ~}{ }^{a}$ \\ ${ }^{a}$ Сибирский федеральный университет \\ Россия, 660041, Красноярск, пр. Свободный, 79 \\ ${ }^{6}$ СКТБ «Наука» КНЦ СО РАН \\ Россия, 660049, Красноярск, пр. Мира, 53
}

На основании анализа научно-технической литературы и теоретических исследований путем построения политермических разрезов многокомпонентных систем предложено

(C) Siberian Federal University. All rights reserved

* Corresponding author E-mail address: uskov59@mail.ru 
два состава лигатур для выплавки новых сплавов на основе серебра. В статье представленьл результаты опытно-промышленных исследований по получению и обработке новых сплавов. Проведена оценка свойств и структуры полученных литых и деформированных полуфабрикатов из новых серебряных ювелирных сплавов 925-й пробы.

Ключевые слова: ювелирный сплав, микроструктура, политермические разрезы.

\section{Введение}

Цель работы - получение новых составов серебряного ювелирного сплава белого цвета 925-й пробы и проволоки на его основе со стабильными физико-механическими характеристиками для производства ювелирных цепей. Объектом исследований является разработка составов лигатур для выплавки сплавов на основе серебра.

В качестве требований к составу сплава и физико-механическим характеристикам деформированных полуфабрикатов и проволоки регламентируется следующее:

- химический состав сплава не должен содержать никель;

- сплав должен иметь высокую коррозионную стойкость;

- микротвердость промежуточных полуфабрикатов и проволоки в отожженном состоянии должна быть в пределах 90-110 HV.

При обсуждении постановки задачи о разработке новых сплавов часто упоминается создание сплавов с «заранее заданными свойствами». Такая постановка задачи допускает, что заданные свойства могут быть любыми, в том числе недостижимыми, имеющимися в нашем распоряжении средствами. Разумнее говорить об оптимальных свойствах оптимальных сплавов, которые обладают наивысшим уровнем одного важнейшего свойства при выполнении определенных ограничений по другим контролируемым свойствам. Синтез сплавов направлен на разработку именно таких оптимальных сплавов.

Единственным путем окончательного выбора состава сплавов выступает опыт. Решить эту задачу путем переборов всех возможных комбинаций элементов практически невозможно. Это именно та ситуация, которая требует для своего решения системного подхода $[1,2]$.

Исходя из требований на сплав основой ювелирного сплава белого цвета 925-й пробы для изготовления цепей является серебро, основными легирующими элементами - $\mathrm{Cu}$ и $\mathrm{Zn}$, в качестве микродобавок взяли In как компонент, создающий фазы - упрочнители, $\mathrm{Sn}$ - как компонент антисульфиданта и $\mathrm{Si}$ - в качестве модифицирующей добавки.

На основании анализа научно-технической литературы и теоретических исследований путем построения политермических разрезов многокомпонентных систем предложено два состава лигатур для выплавки новых сплавов на основе серебра 925-й пробы.

Сплав 1: $\mathrm{Ag}-93,0 \%$; $\mathrm{Cu}-4,47 \% ; \mathrm{Zn}-2,30 \%$; $\mathrm{In}-0,07 \%$; $\mathrm{Sn}-0,09 \%$; $\mathrm{Si}-0,07 \%$.

Сплав 2: $\mathrm{Ag}-93,0 \% ; \mathrm{Cu}-4,54 \% ; \mathrm{Zn}-2,30 \% ; \mathrm{In}-0,07 \% ; \mathrm{Sn}-0,09 \%$.

Лигатура для сплава 1: $\mathrm{Cu}-63,82 \% ; \mathrm{Zn}-32,87 \%$; $\mathrm{In}-1 \%$; $\mathrm{Sn}-1,31 \%$; $\mathrm{Si}-1 \%$.

Лигатура для сплава 2: $\mathrm{Cu}-64,82 \% ; \mathrm{Zn}-32,87 \%$; $\mathrm{In}-1 \%$; $\mathrm{Sn}-1,31 \%$.

Серебряные сплавы 1 и 2 были выплавлены из лигатур, учитывая их температуры ликвидус и солидус, рассчитаные по методике, разработанной профессором В.С. Биронтом [3]. 


\section{Результаты испытаний механических свойств}

Анализ результатов испытаний механических свойств (рис. 1) показал, что максимальный предел прочности наблюдается у сплава 1, в начале образца содержащего кремний, и составляет $\sigma_{\mathrm{B}}=247$ МПа и $\sigma_{\mathrm{B}}=245$ МПа в конце слитка. У сплава 2 соответственно $\sigma_{\mathrm{B}}=243$ МПа в начале и $\sigma_{\mathrm{B}}=241$ МПа в конце слитка.

Предел текучести в сплаве 1 в начале и конце слитка практически одинаков: $\sigma \mathrm{T}=167$ и 169 МПа соответственно (рис. 2). В сплаве 2 в начальной части слитка предел текучести бт=162 МПа, а в конце слитка - бт=169 МПа. Упругие свойства сплава 1 связаны, очевидно, с добавкой кремния, который обладает ковалентной связью, что и повышает предел текучести по сравнению со сплавом 2.

Пластические характеристики сплавов (рис. 3) очень высоки, что связано со структурой однородного твердого раствора. В начале и конце слитков удлинение несколько разное и составляет соответственно в сплаве $1 \delta=53$ и $41 \%$, в сплаве $2 \delta=47$ и $44 \%$.

Микротвердость сплавов 1 и 2 практически одинакова в начале и конце слитков (108 и $100 \mathrm{HV}$ ) соответственно (рис. 4). Это объяснимо тем, что структурный и фазовый состав сплавов практически одинаков, а микродобавки кремния влияют только на формирование структуры (модифицирование).

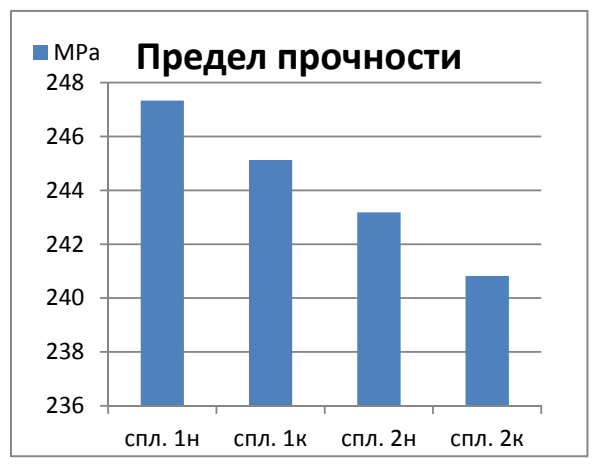

Рис. 1. Предел прочности при испытании на растяжение сплавов 1 и 2 (н - начало слитка, к - его конец)

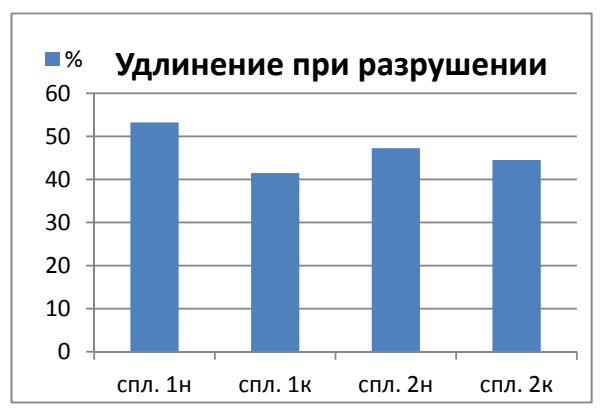

Рис. 3. Удлинение при разрушении сплавов 1 и 2 (н - начало слитка, к - его конец)

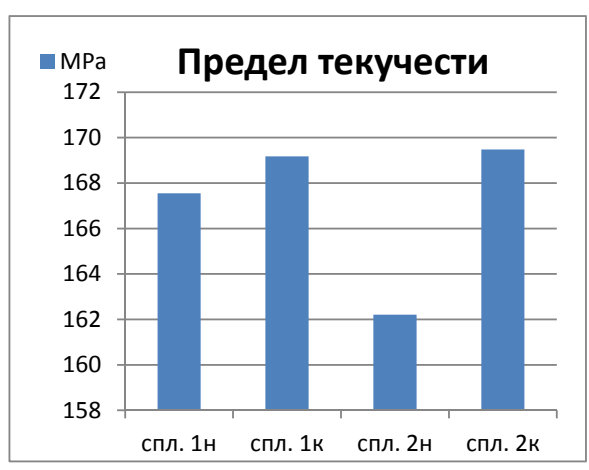

Рис. 2. Предел текучести сплава 1 и 2 (н - начало слитка, к - его конец)

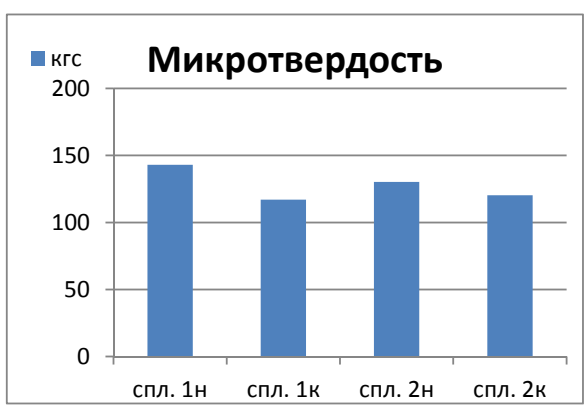

Рис. 4. Микротвердость сплава 1 и 2 (н - начало слитка, к - его конец) 


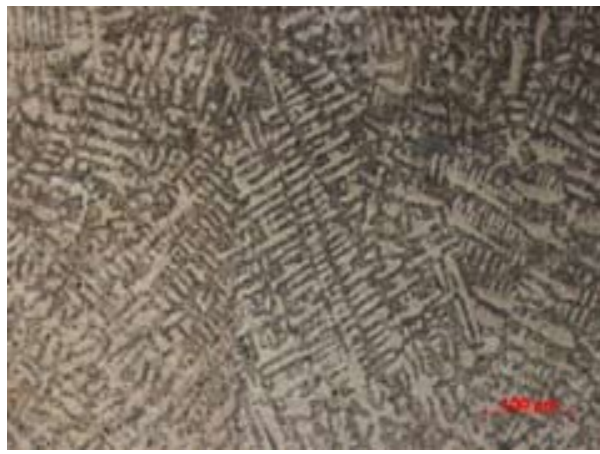

Рис. 5. Микроструктура сплава 1 в литом состоянии. $\mathrm{x} 200$

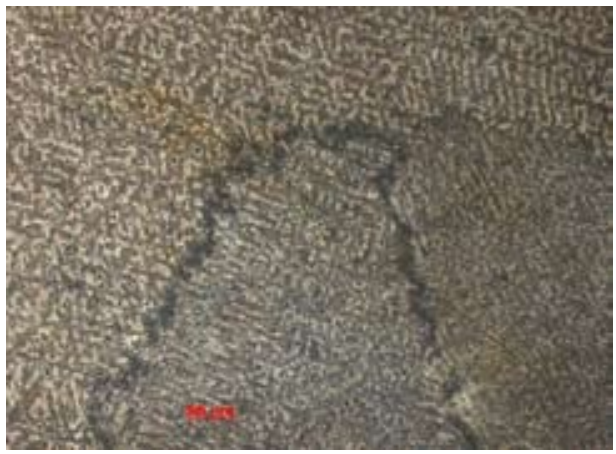

Рис. 6. Микроструктура сплава 2 в литом состоянии. $\mathrm{x} 200$

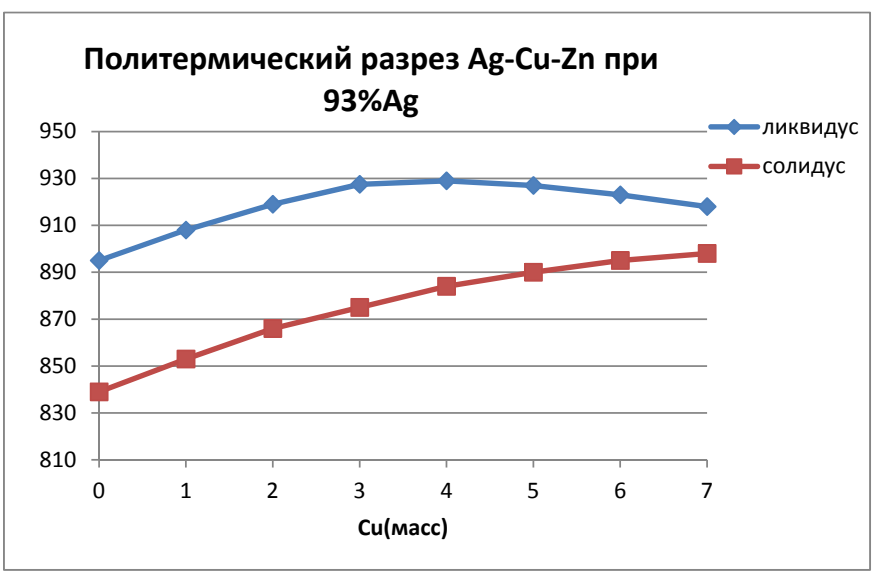

Рис. 7. Политермический разрез системы $\mathrm{Ag}-\mathrm{Cu}-\mathrm{Zn}$, Содержание серебра 93 \%

Микроструктуры сплавов 1 и 2 имеют дендритное строение (рис. 5, 6). Особенно четко это проявляется в сплаве 1, который содержит кремний.

Микроструктура сплавов определяет их механические свойства, которые в итоге оцениваются потребителем. Прочностные характеристики были исследованы в начале и в конце образцов. Во всех случаях получилось, что в начальной части отливок в обоих сплавах прочностные характеристики выше, а на концах - ниже, что, очевидно, связано с более равномерным прогревом металла по сечению.

Был построен политермический разрез системы $\mathrm{Ag}-\mathrm{Cu}-\mathrm{Zn}$ (рис. 7), из чего видно, что минимальный интервал кристаллизации при содержании меди 7 \%, однако в составе 925-й пробы должно быть определенное количество серебра, а поскольку требуются еще определенные свойства сплава, получаемые дополнительным легированием, то содержание меди в пределах $4,5 \%$ дает разницу в температуре $40^{\circ} \mathrm{C}$, что является приемлемым для литейного сплава. 


\section{Выводы}

Разработанные сплавы успешно прошли деформационную обработку при получении проволоки, операцию цепевязания, пайку звеньев цепи методом порошковой пайки. Над цепями осуществляли операции ковки и алмазной огранки.

На сплав № 1 получен патент РФ № 2513502 «Сплав белого цвета на основе серебра 925-й пробы, модифицированный кремнием».

\section{Список литературы}

[1] Проблемы разработки конструкционных сплавов: пер. с англ. ред. Ю.М. Вайнблат. М.: Металлургия, 1980. $254 \mathrm{c}$.

[2] Гуляев Б.Б. Синтез сплавов. (Основные принципы. Выбор компонентов). М.: Металлургия, 1984. $160 \mathrm{c}$.

[3] Биронт В.С., Довженко Н.Н., Мамонов С.Н. и др. Материаловедение. Металловедение палладия и его сплавов: учеб. пособие. Красноярск: ГУЦМиЗ, 2007. 152 с. 